\title{
Kinetics of the Methylation of a Platinum(II) Diimine Dithiolate Complex
}

Justin J. Stace, ${ }^{\mathrm{a}}$ PJ Ball, ${ }^{\mathrm{b}}$ Vikas Shingade, ${ }^{\mathrm{b}}$ Sayandev Chatterjee, ${ }^{\mathrm{b}}$ Amber Shiveley, ${ }^{\mathrm{b}}$ Wendi L. Fleeman, ${ }^{\mathrm{b}}$ Aaron J. Staniszewski, ${ }^{\mathrm{b}}$ Jeanette A. Krause, ${ }^{\mathrm{b}}$ William B. Connick ${ }^{*}, \mathrm{~b}$

${ }^{1}$ Department of Chemistry \& Physics, Belmont University, 4018WAC, 1900 Belmont Blvd., Nashville, TN 37212

${ }^{2}$ Department of Chemistry, University of Cincinnati, P.O. Box 210172, Cincinnati, OH 452210172

\begin{abstract}
$\operatorname{Pt}(\mathrm{dbbpy})(\mathrm{bdt})$ and Pt(tmphen)(bdt) (dbbpy = 4,4'-di-t-butyl-2,2'-bipyridine; tmphen = 3,4,7,8tetramethyl-1,10-phenanthroline; bdt $^{2-}=1,2$-benzenedithiolate) are reported. $\mathrm{Pt}(\mathrm{dbbpy})(\mathrm{bdt})$ reacts with one equivalent of methyl iodide to give the S-methylated product, $\left[\mathrm{Pt}(\mathrm{dbbpy})\left(\mathrm{CH}_{3} \mathrm{bdt}\right)\right] \mathrm{I}$. The reaction follows second order kinetics with a rate constant of $1.3 \times 10^{-2} \mathrm{M}^{-1} \mathrm{~s}^{-1}$ at $311 \mathrm{~K}$. The accumulated data are consistent with direct nucleophilic attack by the coordinated $\mathrm{bdt}^{2-}$ ligand sulfur atom on the carbon atom of the methyl iodide. Variabletemperature experiments yield an Arrhenius activation energy of $51 \pm 3 \mathrm{~kJ} / \mathrm{mol}$. Activated complex reaction theory yields an enthalpy and entropy of activation of $48 \pm 2 \mathrm{~kJ} / \mathrm{mol}$ and $-125 \pm$ $7 \mathrm{~J} /(\mathrm{mol} \mathrm{K})$, respectively, consistent with an $\mathrm{S}_{\mathrm{N}} 2$ reaction mechanism. The structure of the monosulfinate adduct, $\mathrm{Pt}(\mathrm{dbbpy})\left(\mathrm{bdtO}_{2}\right)$, also is reported. The fluid-solution luminescence of $\operatorname{Pt}(\mathrm{tmphen})(\mathrm{bdt})$ is concentration dependent and characterized by a $1591 \pm 41 \mathrm{~ns}$ lifetime and 2.6 $\pm 0.2 \%$ quantum yield at infinite dilution. The observed chemical reactivity and self-quenching behavior have important implications for the design of photochemical devices based on the platinum(II) diimine dithiolate chromophore.
\end{abstract}

Keywords: platinum diimine dithiolate complexes; kinetics of sulfur ligand methylation; X-ray crystal structures; emission spectroscopy; self-quenching 


\section{Introduction}

Since Camassei et al. first reported emissions from square-planar platinum(II) diimine complexes [1], there has been considerable interest in the photophysical properties and photochemical reactivity of these systems [2-12], including complexes with dithiolate ligands [2, 13-16]. Potential applications include light-emitting diodes [17-20], chemical sensing [7, 20, $21]$, and catalysts for light-to-chemical energy conversion schemes [22, 23]. The LUMO of these complexes has mainly diimine character. The presence of opposing thiolate donor groups destabilizes the HOMO and results in a lowest excited state with significant thiolate-to-diimine charge-transfer character. The resulting complexes have interesting spectroscopic, electrochemical, chemical, photophysical, and photochemical properties. One example is the fact that the fluid solution emission lifetimes of these complexes are concentration dependent, which is suggestive of dynamic and/or static quenching [8, 24]. Surprisingly, this behavior has not always been fully considered $[14,25,26]$, although it is surely relevant to efforts to design molecular devices. Interestingly, the expected dependence of the emission quantum yield on concentration has not yet been verified [24].

An example of photochemical activity is the irradiation of solutions of $\operatorname{Pt}(\mathrm{bpy})(\mathrm{bdt})$ (bpy $=2,2^{\prime}$-bipyridine; bdt $^{2-}=1,2$-benzenedithiolate) under aerobic conditions to produce singlet oxygen, which reacts with the complex to form mono- and disulfinate products (Scheme 1) [16].

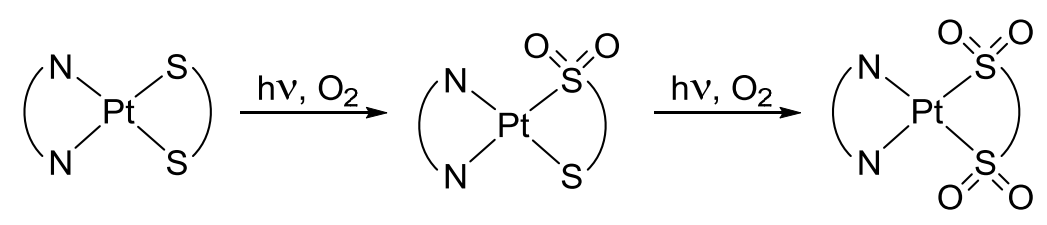

Scheme 1: Photooxidation of Pt(bpy)(bdt).

On the other hand, photolysis of $\mathrm{Pt}(\mathrm{dbbpy})(\mathrm{dpdt})\left(\mathrm{dpdt}^{2-}=\right.$ meso-1,2-diphenyl-1,2ethanedithiolate) in the presence of oxygen produces the corresponding dithiolene product [15]. 


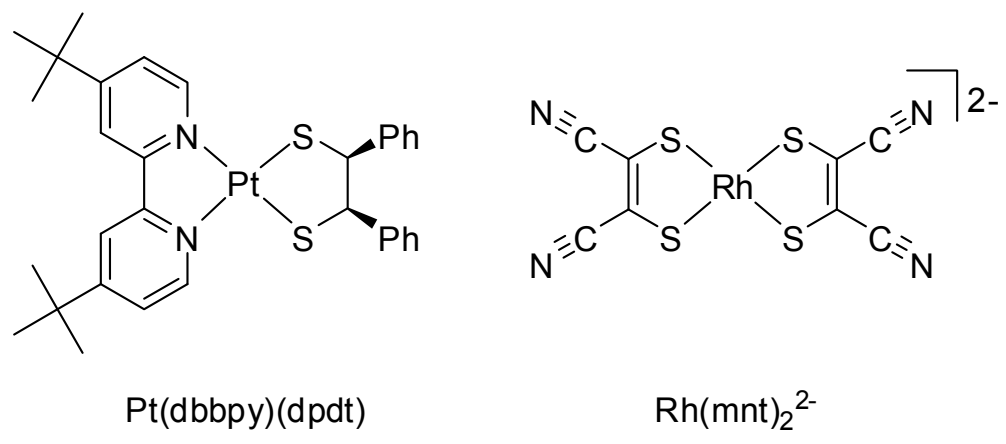

The nucleophilic S atoms of the bdt ${ }^{2-}$ ligand bonded to platinum(II) also may be alkylated in thermal reactions with alkyl halides [16, 27]. However, the preference for oxidation at sulfur rather than the metal is not readily predicted, as there are several reports of oxidative addition reactions and thiolate alkylation reactions of $\mathrm{d}^{8}$-electron metal complexes with multiple thiolate donor groups [28-31]. For example, Vlček reported that $\mathrm{Rh}(\mathrm{mnt})_{2}{ }^{2-}\left(\mathrm{mnt}^{2-}=\right.$ maleonitriledithiolate) reacts with methyl iodide without sulfur methylation [32], whereas VanDerveer and Eisenberg found that $\mathrm{Rh}(\mathrm{L})(\mathrm{mnt})^{-}(\mathrm{L}=1,5$-cyclooctadiene or norbornadiene) is readily methylated at sulfur [33].

Surprisingly little attention has been given to S-alkylation of platinum complexes. By contrast, several groups have investigated related nickel complexes and determined kinetic parameters of their alkylation reactions [34-38]. More recently, Darensbourg and co-workers have investigated the alkylation of an array of nickel(II) thiolate complexes with various electrophiles [39-42]. Ashby et al. [43] have suggested that the interaction between the occupied $\mathrm{d} \pi$ nickel orbitals and the p-type sulfur lone pair enhances the nucleophilicity of the coordinated thiolate in such systems.

With the objective of evaluating the relative susceptibilities of the platinum(II) center and thiolate ligands in diimine dithiolate complexes, we have investigated the reaction of $\operatorname{Pt}(\mathrm{dbbpy})(\mathrm{bdt})(\mathrm{dbbpy}=4-4$ '-di-t-butyl-2,2'-bipyridine) with methyl iodide and found that this 
yields exclusively the singly S-methylated product, $\mathrm{Pt}(\mathrm{dbbpy})\left(\mathrm{CH}_{3} \mathrm{bdt}\right)^{+}$. We also report the crystal structure of the monosulfinate analogue, $\mathrm{Pt}(\mathrm{dbbpy})\left(\mathrm{bdtO}_{2}\right)$, as well as the concentration dependence of the emission lifetime and quantum yield of the related complex, $\operatorname{Pt}(\operatorname{tmphen})(\mathrm{bdt})$.

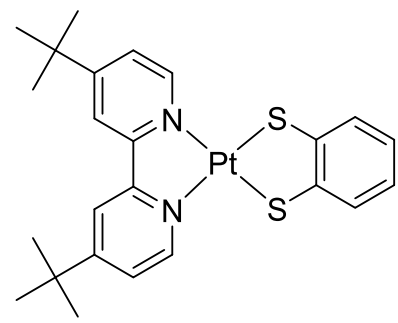

Pt(dbbpy)(bdt)

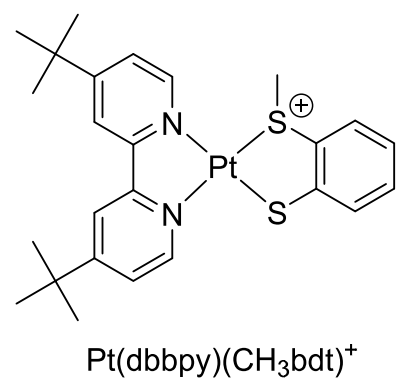

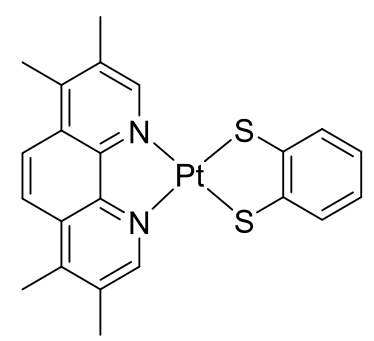

Pt(tmphen)(bdt)

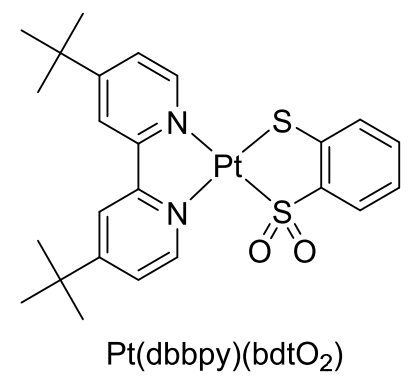

\section{Experimental Section}

\subsection{Materials and methods}

All reagents were obtained from Aldrich, Pressure Chemical, or Acros. $\mathrm{Pt}(\mathrm{dbbpy}) \mathrm{Cl}_{2}$ was prepared from $\mathrm{K}_{2} \mathrm{PtCl}_{4}$ as previously described [44] and washed with copious amounts of water to remove trace $\mathrm{HCl}$. Deuterated solvents for NMR spectroscopy were obtained from Cambridge Isotope Laboratories. Acetonitrile, dichloromethane and chloroform were distilled from calcium hydride under argon, all other solvents used for synthesis and physical measurements were purged with argon prior to use. Elemental analyses were performed by Atlantic Microlabs. ${ }^{1} \mathrm{H}$ NMR spectra were recorded using a Bruker AC-250 or Bruker $400 \mathrm{MHz}$ instrument; chemical shifts are referenced in ppm vs. TMS. In the case of $\mathrm{Pt}(\mathrm{dbbpy})\left(\mathrm{bdtO}_{2}\right)$, spectra were assigned 
based on 2-dimensional COSY data. Steady-state UV-visible absorption spectra were recorded using a HP-8453 diode array spectrophotometer. Mass spectra were obtained using an Ionspec HiRes ESI-FTICRMS or a Micromass Q-TOF-II instrument. Observed isotope patterns were in excellent agreement with those calculated based on natural isotopic abundances.

For fluid solution emission studies, solutions of $\mathrm{Pt}(\mathrm{tmphen})(\mathrm{bdt})$ were placed in a reservoir connected to a $1-\mathrm{cm}$ quartz cuvette and subjected to three freeze-pump-thaw cycles to give a final pressure over frozen solution of less than $<10^{-5}$ torr. Samples were monitored by UV-visible absorption spectroscopy, and for any given set of measurements, decomposition was estimated to be less than 3\%. Emission and emission lifetime measurements were carried out using previously described instrumentation [45]. The standard deviation $(\sigma)$ for the experimental decay rates $\left(k^{\prime}\right)$ was estimated to be $3 \%$ of $k^{\prime}$.

Emission quantum yields were determined relative to cresyl violet in $\mathrm{MeOH}$ (Acros, spectroscopic grade) $\left(\Phi^{\prime \prime}=0.54\right)[46]$. The absorbance of both the standard and the sample at the excitation wavelength were between 0.1 and 0.3 a.u. and were within \pm 0.01 a.u. of each other. The emission quantum yields, $\Phi^{\prime}$, were calculated using Equation 1 [47]:

$$
\frac{\Phi^{\prime}}{\Phi^{\prime \prime}}=\frac{\left(1-10^{A_{l} l}\right) \eta_{\mathrm{s}}^{2} I_{\mathrm{s}}}{\left(\begin{array}{c}
\left(1-10^{\mathrm{A} l}\right) \\
\text { Equation } 1
\end{array} \eta_{\mathrm{r}}^{2} I_{\mathrm{r}}\right.}
$$

where $A$ = absorbance of the platinum diimine dithiolate sample $\left(A_{s}\right)$ or cresyl violet reference $\left(A_{\mathrm{r}}\right), l=$ pathlength of the cuvette $(1 \mathrm{~cm}), \eta=$ refractive index of the sample $\left(\mathrm{in}_{\mathrm{CHCl}}\right)$ or reference (in $\mathrm{MeOH}$ ) solvents, and $I=$ integrated emission intensity of the sample from 650-700 $\mathrm{nm}$. Values of the standard deviation $(\sigma)$ for $\Phi^{\prime}$ were estimated by propagation of the estimated $\sigma$ for $A(0.0035$ a.u. $), I(2 \%)$ and concentration. $\Phi^{\prime}$ was invariant within experimental error for 
excitation wavelengths from 460 to $610 \mathrm{~nm}$. Details of the analysis of the photophysical data and self-quenching are given in the Supplementary Material. Parameter estimates are reported with $\pm 2 \sigma$ values.

\subsection{Kinetics Studies}

Time-resolved UV-visible absorption data were collected using an Applied Photophysics (AP) SX18MV Stopped-Flow instrument fitted with a RISC Acorn PC and A/D converter, 150W halogen lamp, monochromator, rectangular 2- or 10-mm pathlength quartz cell $(20 \mu \mathrm{L})$ and photomultiplier tube. The stopped-flow instrument was purged with argon-saturated solvent prior to use, and the Teflon drive syringe pistons were bathed in an argon stream. The drive syringes, flow circuit plumbing and observation cell were thermostated to $\pm 0.1^{\circ} \mathrm{C}$ using a Fisher Isotemp 3016 recirculator, running argon-purged coolant (20\% aqueous ethanol). Reagent solutions were prepared fresh daily and kept under argon prior to use. The reagents were withdrawn into gastight syringes using stainless steel needles and quickly transferred to the stopped-flow instrument, using three-way valves for the rigorous exclusion of oxygen. Reagent solutions were temperature equilibrated for at least 10 minutes prior to mixing. Data were typically collected for 100 seconds and analyzed at single wavelengths or globally (for multiwavelength data sets), using AP Pro-Kineticist (Pro-K) software run in a Windows environment.

Data collected within 5 seconds of mixing of chloroform solutions of Pt(dbbpy)(bdt) and methyl iodide were contaminated by a solvent compression artifact, and therefore the shorter time data points were not included in the kinetics analyses. As the spectrum of the mixture at 5 seconds was nearly identical to that obtained without added $\mathrm{CH}_{3} \mathrm{I}$, this procedure did not remove 
crucial mechanistic information. Principal component analysis of reaction data sets also was carried out on a Mathematica 8 platform using singular value decomposition, where the data matrix is given by the $\boldsymbol{u} \cdot \boldsymbol{v} \cdot \boldsymbol{w}^{\mathrm{T}}$ product of matrices, where $\boldsymbol{u}$ and $\boldsymbol{w}$ are unitary matrices and $\boldsymbol{v}$ is a diagonal matrix. Inspection of plots of eigenvalues, Malinowski's RE, and autocorrelations of $\boldsymbol{u}$, and plots of reconstructed spectral data are consistent with the presence of only two significant principal components. Data were fit to the simplest model that described the spectral changes, namely a reaction that was first order in metal complex and first order in methyl iodide. The validity of the mechanism was assessed by inspection of residual plots and the extracted UVvisible spectra of the electronic spectrum of reagents. An essentially invariant rate constant over a wide range of reagent concentrations also lent support to the proposed mechanism.

The energy of activation $\left(51 \pm 2.5 \mathrm{~kJ} \mathrm{~mol}^{-1}\right)$ and the Arrhenius pre-exponential factor (5.2 $\left.\pm 0.3 \times 10^{6} \mathrm{M}^{-1} \mathrm{~s}^{-1}\right)$ were determined by an Arrhenius plot based on Equation 2 .

$$
\ln (k)=\ln (A)-\frac{E_{a}}{R T}
$$

Equation 2

Transition state theory for nonionic reactants and activated complexes yields Equations 3 and 4, where $E_{\mathrm{a}}$ is the Arrhenius energy of activation, $R$ is the ideal gas constant, $A$ is the preexponential factor, $h$ is Plank's constant, $c^{\mathrm{o}}$ is the standard concentration, $k_{\mathrm{B}}$ is Boltzmann's constant, and $e$ is the fundamental charge $[48,49]$. The enthalpy $\left(\Delta H^{\ddagger}\right)$ and entropy $\left(\Delta S^{\ddagger}\right)$ of the formation of the activated complex were estimated from Equations 3 and 4.

$$
\Delta H^{\ddagger}=E_{a}-R T
$$




$$
\Delta S^{\ddagger}=\frac{\ln \left(A h c^{\circ}\right)}{k_{B} T e}
$$

Equation 4

\subsection{Synthesis}

\subsubsection{Pt(dbbpy)(bdt)}

A slurry of $\mathrm{Pt}(\mathrm{dbbpy}) \mathrm{Cl}_{2}(0.210 \mathrm{~g}, 0.393 \mathrm{mmol})$ in $\mathrm{DMF}(35 \mathrm{~mL})$ was warmed to $35^{\circ} \mathrm{C}$ to yield a yellow solution. The solution was cooled to room temperature, and $\mathrm{AgNO}_{3}(0.138 \mathrm{~g}$, $0.812 \mathrm{mmol}$ ) was added. After stirring in the dark for $1 \mathrm{hr}$, the cloudy mixture was filtered through Celite to give a yellow filtrate. Dropwise addition of an aqueous potassium hydroxide solution (7.4 mL, $\mathrm{pH}=10)$ of 1,2-benzenedithiol $\left(\mathrm{bdtH}_{2}, 0.374 \mathrm{mmol}\right)$ immediately yielded a red precipitate. After cooling to $0^{\circ} \mathrm{C}$ and stirring for 45 minutes, the dark red powder was isolated by filtration, washed with water $(4 \times 3 \mathrm{~mL})$ and cold ethanol $(2 \times 1 \mathrm{~mL})$, and dried under vacuum $(0.183 \mathrm{~g},>99 \%$ yield $)$. The product was purified by dissolution in dichloromethane $(8 \mathrm{~mL})$, followed by addition of $\mathrm{MeOH}: \mathrm{H}_{2} \mathrm{O}(90: 10$ ratio, $90 \mathrm{~mL})$. After cooling to $-6^{\circ} \mathrm{C}$ overnight, the mixture was centrifuged or filtered leaving a red solid that was washed with water and methanol and dried overnight under vacuum ( $0.139 \mathrm{~g}, 76 \%$ yield). Anal. Calcd for $\mathrm{C}_{24} \mathrm{~N}_{2} \mathrm{H}_{28} \mathrm{~S}_{2} \mathrm{Pt}$ : C, 47.75; H, 4.67; N, 4.64. Found: C, 47.62; H, 4.55; N, 4.64. ${ }^{1} \mathrm{H}$ NMR (d $\left.\mathrm{d}_{6}-\mathrm{DMSO}\right) \delta(\mathrm{ppm}): 1.44(18 \mathrm{H}$, s, $\left.\mathrm{CH}_{3}\right), 6.70(2 \mathrm{H}, \mathrm{t}, \mathrm{CH}), 7.21(2 \mathrm{H}, \mathrm{d}, \mathrm{CH}), 7.79(2 \mathrm{H}, \mathrm{d}, \mathrm{CH}), 8.65(2 \mathrm{H}, \mathrm{s}, \mathrm{CH}), 8.96(2 \mathrm{H}, \mathrm{d}$, CH). UV-vis, $\lambda\left(\mathrm{M}^{-1} \mathrm{~cm}^{-1}\right)\left(\mathrm{CHCl}_{3}\right): 351$ (2650), 577 (7370); $\left(\mathrm{CH}_{2} \mathrm{Cl}_{2}\right): 294$ (23700), 304 (28300), 556 (7300). MS-ESI (m/z): 604.1 ([Pt(dbbpy)(bdt)]H $\left.\mathrm{H}^{+}\right), 1207.3\left([\mathrm{Pt}(\mathrm{dbbpy})(\mathrm{bdt})]_{2} \mathrm{H}^{+}\right)$.

\subsubsection{Pt(tmphen)(bdt)}


Two equivalents of $\mathrm{AgNO}_{3}(0.0676 \mathrm{~g}, 0.398 \mathrm{mmol})$ were added to a solution of $\mathrm{Pt}(\mathrm{tmphen}) \mathrm{Cl}_{2}$ (tmphen = 3,4,7,8-tetramethyl-1,10-phenanthroline) [50] (0.100 g, $\left.0.199 \mathrm{mmol}\right)$ in $15 \mathrm{~mL}$ DMF. After stirring for $3 \mathrm{hrs}$, the solution was filtered through Celite and the filtrate was added dropwise to a mixture of bdtH $\mathrm{H}_{2}(45.8 \mu \mathrm{L}, 0.398 \mathrm{mmol})$ in $800 \mu \mathrm{L}$ of $1 \mathrm{M} \mathrm{KOH}$. After stirring for 30 minutes, the purple-red solid was collected by filtration and then recrystallized by vapor diffusion of diethyl ether into a pyridine solution. ${ }^{1} \mathrm{H}$ NMR (d-DMSO) $\delta(\mathrm{ppm}): 8.99$ (s, 2H), $8.32(\mathrm{~s}, 2 \mathrm{H}), 7.27$ (d, 2H, J=3 Hz), $6.73(\mathrm{~d}, 2 \mathrm{H}, J=9 \mathrm{~Hz}), 2.72(\mathrm{~s}, 6 \mathrm{H}), 2.61$ (s, 6H). Anal. Calcd. for $\mathrm{C}_{22} \mathrm{H}_{20} \mathrm{~N}_{2} \mathrm{~S}_{2} \mathrm{Pt}: \mathrm{C}, 46.23 ; \mathrm{H}, 3.53 ; \mathrm{N}, 4.90$. Found: C, 46.22; H, 3.53; N, 4.97. UV-vis, $\lambda\left(\mathrm{M}^{-1} \mathrm{~cm}^{-1}\right)\left(\mathrm{CH}_{2} \mathrm{Cl}_{2}\right): 276$ (46000), 310sh (1200), 420sh (3700), 526 (7000). MS-ESI (m/z): $572.08\left(\mathrm{Pt}(\mathrm{tmphen})(\mathrm{bdt})^{+}\right)$.

\subsection{3. $\left[\mathrm{Pt}(\mathrm{dbbpy})\left(\mathrm{CH}_{3} b d t\right)\right]\left(\mathrm{PF}_{6}\right)$}

A deep red solution of $\mathrm{Pt}(\mathrm{dbbpy})(\mathrm{bdt})(23.7 \mathrm{mg}, 39.3 \mu \mathrm{mol})$ in dichloromethane $(6 \mathrm{~mL})$ and $\mathrm{CH}_{3} \mathrm{I}$ ( $3 \mathrm{~mL}, 1200$ fold excess) was refluxed for 30 minutes under argon, during which time the solution color turned pale yellow. After cooling to room temperature, the volume was reduced to $2 \mathrm{~mL}$ under an argon stream. Approximately $9 \mathrm{~mL}$ of diethyl ether were added via cannula to give a vibrant, bright yellow precipitate. After cooling to $-6^{\circ} \mathrm{C}$, the product was collected by filtration, washed with hexanes $(4 \times 2 \mathrm{~mL})$, and dried under vacuum. The resulting product, [ $\left.\mathrm{Pt}(\mathrm{dbbpy})\left(\mathrm{CH}_{3} \mathrm{bdt}\right)\right] \mathrm{I}(21.6 \mathrm{mg}, 74 \%)$, is stable in the solid state, but photosensitive in solution. UV-vis, $\lambda\left(\mathrm{M}^{-1} \mathrm{~cm}^{-1}\right)\left(\mathrm{CHCl}_{3}\right): \lambda_{\max }(\mathrm{nm}), \varepsilon\left(\mathrm{M}^{-1} \mathrm{~cm}^{-1}\right): 301$ (22000), 456 (3300). To a solution of yellow $\left[\mathrm{Pt}(\mathrm{dbbpy})\left(\mathrm{CH}_{3} \mathrm{bdt}\right)\right] \mathrm{I}(12.6 \mathrm{mg})$ in $5 \mathrm{~mL}$ of argon-saturated ethanol was added $9.5 \mathrm{~mL}$ of a $0.296 \mathrm{M}$ aqueous solution of $\mathrm{NH}_{4} \mathrm{PF}_{6}$ to give a yellow precipitate. The alcohol was removed under argon flow, and the solution was cooled to $\sim 0^{\circ} \mathrm{C}$. The yellow solid was 
recovered by filtration, washed with water $(5 \times 2 \mathrm{~mL})$ and diethyl ether $(3 \times 1 \mathrm{~mL})$, and dried under vacuum (21.6 mg, 88.9\% yield). ${ }^{1} \mathrm{H}$ NMR (d 6 -DMSO) $\delta(\mathrm{ppm}): 1.46\left(18 \mathrm{H}, \mathrm{s}, \mathrm{CH}_{3}\right), 3.00(3 \mathrm{H}, \mathrm{s}$, $\left.\mathrm{CH}_{3}\right), 7.10(\mathrm{H}, \mathrm{t}, \mathrm{CH}), 7.28(\mathrm{H}, \mathrm{t}, \mathrm{CH}), 7.52(\mathrm{H}, \mathrm{d}, \mathrm{CH}), 7.71(\mathrm{H}, \mathrm{d}, \mathrm{CH}), 7.92(\mathrm{H}, \mathrm{d}, \mathrm{CH}), 7.93$ $(\mathrm{H}, \mathrm{d}, \mathrm{CH}), 8.80(2 \mathrm{H}, \mathrm{m}, \mathrm{CH}), 8.84(\mathrm{H}, \mathrm{d}, \mathrm{CH}), 8.93(\mathrm{H}, \mathrm{d}, \mathrm{CH}) . \mathrm{UV}$-vis, $\lambda\left(\mathrm{M}^{-1} \mathrm{~cm}^{-1}\right)\left(\mathrm{CHCl}_{3}\right)$ : 301 (22000), 380 (3100) 456 (3400). MS-ESI (m/z): 618.14 ([Pt(dbbpy)(CH $\left.\left.\left(\mathrm{CH}_{3} \mathrm{bdt}\right)\right]^{+}\right)$.

\subsection{Single Crystal $X$-ray Diffraction}

Crystals of Pt(dbbpy)(bdt) were obtained as dark red, rectangular blocks by diffusion of diethyl ether into a pyridine solution of the complex. Red needle-shaped crystals of $\mathrm{Pt}(\mathrm{dbbpy})\left(\mathrm{bdtO} \mathrm{O}_{2}\right) \cdot \mathrm{DMF} .0 \cdot 25 \mathrm{H}_{2} \mathrm{O}$ grew in minimal light during a 24-month period by partial evaporation of a 5:1 DMF: $\mathrm{H}_{2} \mathrm{O}$ filtrate solution obtained from the synthesis of $\operatorname{Pt}(\mathrm{dbbpy})(\mathrm{bdt})$ (see Supplementary Material). Orange needle-shaped crystals of Pt(tmphen)(bdt) were obtained from pyridine. Details of the X-ray diffraction experiments and crystallographic data are summarized in Supplementary Material.

\section{Results and Discussion}

\subsection{Synthesis and Characterization}

$\operatorname{Pt}(\mathrm{dbbpy})(\mathrm{bdt})$ and $\operatorname{Pt}(\mathrm{tmphen})(\mathrm{bdt})$ were prepared from the reaction of the corresponding $\mathrm{Pt}($ diimine $) \mathrm{Cl}_{2}$ complexes with $\mathrm{AgNO}_{3}$ in $\mathrm{DMF}$ followed by treatment with a basic solution of 1,2-benzenedithiolate. This route is slightly different than those previously reported for $\operatorname{Pt}(\mathrm{dbbpy})(\mathrm{bdt})[25,51]$ and does not require chromatography. The deep red-colored products 
precipitated from solution and were readily isolated by centrifugation or filtration. The identities of the products were verified by elemental analysis, mass spectrometry, ${ }^{1} \mathrm{H}$ NMR spectroscopy, electronic spectroscopy, and X-ray crystallography. The compounds are thermally stable in polar organic solvents, dissolving to give red-to-purple solutions (Figure 1). However, as noted previously for this class of complexes $[32,52]$, the compounds are photosensitive in halogenated solvents and in solutions containing dissolved oxygen. Interestingly, on one occasion the DMF filtrate obtained during synthesis of $\mathrm{Pt}(\mathrm{dbbpy})(\mathrm{bdt})$ was stored in the dark for a 24-month period. Partial evaporation yielded orange-red needles that were shown by X-ray crystallography to contain the monosulfinate adduct, $\mathrm{Pt}(\mathrm{dbbpy})\left(\mathrm{bdtO}_{2}\right)$. Platinum diimine dithiolate complexes are known to sensitize formation of singlet oxygen and react with singlet oxygen to form sulfinate products $[15,16]$; in the present case, the possibility of a slow reaction with ground-state oxygen cannot be fully excluded. 


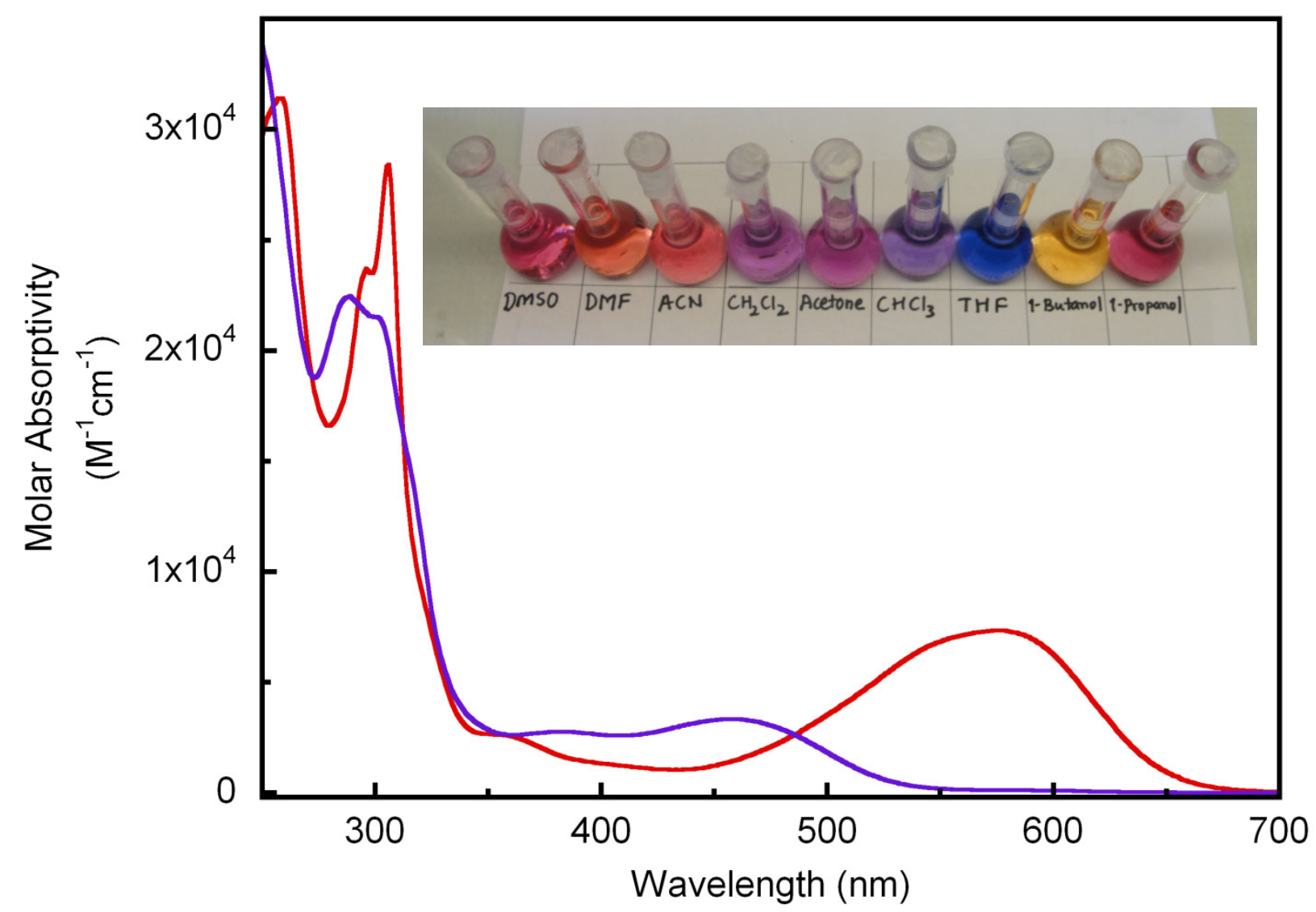

Figure 1: The UV-visible absorption spectrum of $\mathrm{Pt}(\mathrm{dbbpy})(\mathrm{bdt})(\mathrm{red})$ and $\left[\mathrm{Pt}(\mathrm{dbbpy})\left(\mathrm{CH}_{3} \mathrm{bdt}\right)\right] \mathrm{I}$ (blue) in chloroform. Inset shows $60 \mu \mathrm{M}$ solutions of $\mathrm{Pt}(\mathrm{dbbpy})(\mathrm{bdt})$ in DMSO, DMF, acetonitrile, methylene chloride, acetone, chloroform, tetrahydrofuran, $t$-butanol, and 1-propanol.

The electronic absorption spectra of Pt(dbbpy)(bdt) and Pt(tmphen)(bdt) obey Beer's Law and are reminiscent of other platinum diimine dithiolate complexes (Figure 1) [5, 11, 14, $25,26,53,54]$. In accord with the findings of Shultz, Kirk, Kato, and others [26, 51, 55], absorptions near $300 \mathrm{~nm}$ are characteristic of diimine ligand-centered (LC) transitions [4, 5, 24]. The band at $353 \mathrm{~nm}$ in the spectrum of the dbbpy complex is attributable to a ${ }^{1} \operatorname{MLCT}\left[\mathrm{d} \rightarrow \pi_{1} *(\mathrm{bpy})\right]$ transition $[4,5,7,24]$. A solvent-sensitive charge-transfer band occurs at much longer wavelengths (dbbpy, 556; tmphen, $526 \mathrm{~nm}, \mathrm{CH}_{2} \mathrm{Cl}_{2}$ ) and is assigned to a mixed 
metal-ligand-to-ligand charge-transfer (MMLLCT) from the dithiolate to the diimine ligand, coupled to the strongly allowed $d \rightarrow p$ transitions of the metal center $[3,5,8,11,56]$. The color of dissolved complexes is dependent on solvent (inset of Figure 1), and the MMLLCT band maximum shows the expected linear dependence on the $\operatorname{Pt}(\mathrm{NN})(\mathrm{SS})$ solvent polarity scale (Figure S2) [14]. From comparison with Pt(diimine)(3,4-toluenedithiolate) analogs [14], it is evident that substitution of $\operatorname{tdt}^{2-}\left(\mathrm{tdt}^{2-}=\right.$ toluene-3,4-dithiolate) with $\mathrm{bdt}^{2-}$ destabilizes the chargetransfer state by $\sim 200 \mathrm{~cm}^{-1}$.

\subsection{Photophysical Properties of Pt(tmphen)(bdt)}

Because of its high MMLLCT energy, which suggests a long excited-state lifetime [14], we investigated the luminescence and photophysical properties of Pt(tmphen)(bdt). We were particularly interested in the concentration dependencies of the solution emission lifetime and quantum yield, which have not previously been compared in platinum(II) diimine dithiolate systems. In room-temperature methylene chloride, the complex exhibits broad red emission $\left(\lambda_{\max }=700 \mathrm{~nm}\right)$. From the overlap of the emission band with the MMLCT absorption band, the excited state energy was estimated to be $\sim 2.1 \mathrm{eV}$. The transient emission decays are well described by a single-exponential decay function. However, both the emission-decay rate constant and the quantum yields are dependent on platinum concentration $(20-340 \mu \mathrm{M})$ (Figures S3-S5), consistent with an excited-state lifetime $\left(1 / k_{\mathrm{M}}\right)$ and quantum yield for $\operatorname{Pt}(\mathrm{tmphen})(\mathrm{bdt})$ at infinite dilution of $1591 \pm 41 \mathrm{~ns}$ and $2.6 \pm 0.2 \%$, respectively. Thus, $\operatorname{Pt}(\mathrm{tmphen})(\mathrm{bdt})$ has one of the longest excited-state lifetimes of platinum(II) diimine dithiolate complexes reported to date. Scheme 2 depicts a possible mechanism to account for the self- 
quenching behavior in which a collisional encounter between an excited-state $\left(\mathrm{Pt}^{*}\right)$ and groundstate complex $(\mathrm{Pt})$ produces an excimer, $[\mathrm{Pt} \cdots \mathrm{Pt}]^{*}$. This model has been used to account for the self-quenching reactions of other platinum(II) diimine complexes [8, 23, 24, 57-62]. However, for diimine dithiolate complexes, excimer emission has not been reported, and the model has not been tested against quantum yield data $[8,16,57,60]$. In the case of $\mathrm{Pt}(\mathrm{tmphen})(\mathrm{bdt})$, we were unable to detect emission attributable to an excimer, and therefore a static quenching mechanism cannot be fully excluded. Under the assumption of the correctness of the excimer model, simulations were used to narrow the range of possible parameter values in Scheme 2 (see Supplementary Material). The resulting range of equilibrium constants $\left(k_{\mathrm{DM}} / k_{\mathrm{MD}}, 10^{2}-10^{3} \mathrm{M}^{-1}\right)$ are consistent with a more weakly bonded excimer than found for Pt(4,7-diphenyl-1,10phenanthroline $)(\mathrm{CN})_{2}\left(\sim 10^{4} \mathrm{M}^{-1}\right)$ [61].

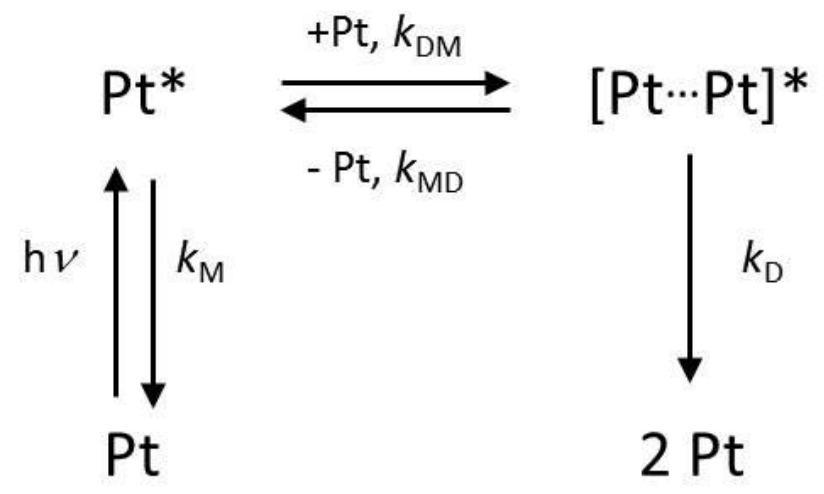

Scheme 2. Proposed mechanism of self-quenching of excited Pt(tmphen)(bdt).

\subsection{Crystal Structures}

ORTEP diagrams of $\mathrm{Pt}(\mathrm{dbbpy})(\mathrm{bdt}), \mathrm{Pt}(\mathrm{tmphen})(\mathrm{bdt})$ and $\mathrm{Pt}(\mathrm{dbbpy})\left(\mathrm{bdtO}_{2}\right)$ are shown in Figure 2 and key metrical data are summarized in Table S2. $\mathrm{Pt}(\mathrm{dbbpy})\left(\mathrm{bdtO} \mathrm{O}_{2}\right) \cdot \mathrm{DMF} \cdot 0.25 \mathrm{H}_{2} \mathrm{O}$ 
crystallizes as two independent molecules with solvent in the lattice, whereas Pt(dbbpy)(bdt) and $\mathrm{Pt}(\mathrm{tmphen})(\mathrm{bdt})$ crystallize without solvent. For all three structures, the coordination geometries are approximately square-planar, and the N-donor and S-donor chelates have bite angles of approximately $79^{\circ}$ and $89^{\circ}$, respectively and as expected [51]. Excluding the $t$-butyl groups, the complexes are nearly planar in the $\operatorname{Pt}(\mathrm{dbbpy})(\mathrm{bdt})$ and $\mathrm{Pt}(\mathrm{tmphen})(\mathrm{bdt})$ structures. For $\operatorname{Pt}(\mathrm{dbbpy})(\mathrm{bdt})$, the molecule is nearly planar with rms deviation of $0.054 \AA$ for the nonhydrogen atoms (excluding the $t$-butyl groups). The Pt atom lies within $0.008 \AA$ of the coordination plane defined by the four bonded atoms. By contrast, both molecules of $\mathrm{Pt}(\mathrm{dbbpy})\left(\mathrm{bdtO}_{2}\right)$ are slightly bowed along the longest molecular dimension (rms deviations: $\mathrm{A}$, $0.138 \AA ; \mathrm{B}, 0.160 \AA$ ) and the Pt atom is displaced further from the coordination plane (A: 0.044, B: $0.054 \AA$ ). Similar bowing has been noted for related Pd(II) and Pt(II) bipyridyl monosulfinate and disulfinate analogs, $\mathrm{M}(\mathrm{bpy})\left(\mathrm{bdtO}_{2}\right)$ and $\mathrm{M}(\mathrm{bpy})\left(\mathrm{bdtO}_{4}\right)$, respectively $[16,63]$. The metal-ligand bond distances also show the expected pattern. The Pt-S(sulfinate) distances (A: 2.2272(12), B: 2.2181(11) §̊) are significantly shorter than the Pt-S(thiolate) distances $(2.2547(8)-2.2649(11) \AA)$, which fall in the typical range $[2,16,19,64]$. By contrast the CS(sulfinate) bond lengths (A: 1.806(5), B: 1.800(5) Å) are slightly longer than their C-S(thiolate) counterparts $(1.75-1.77 \AA)$. 

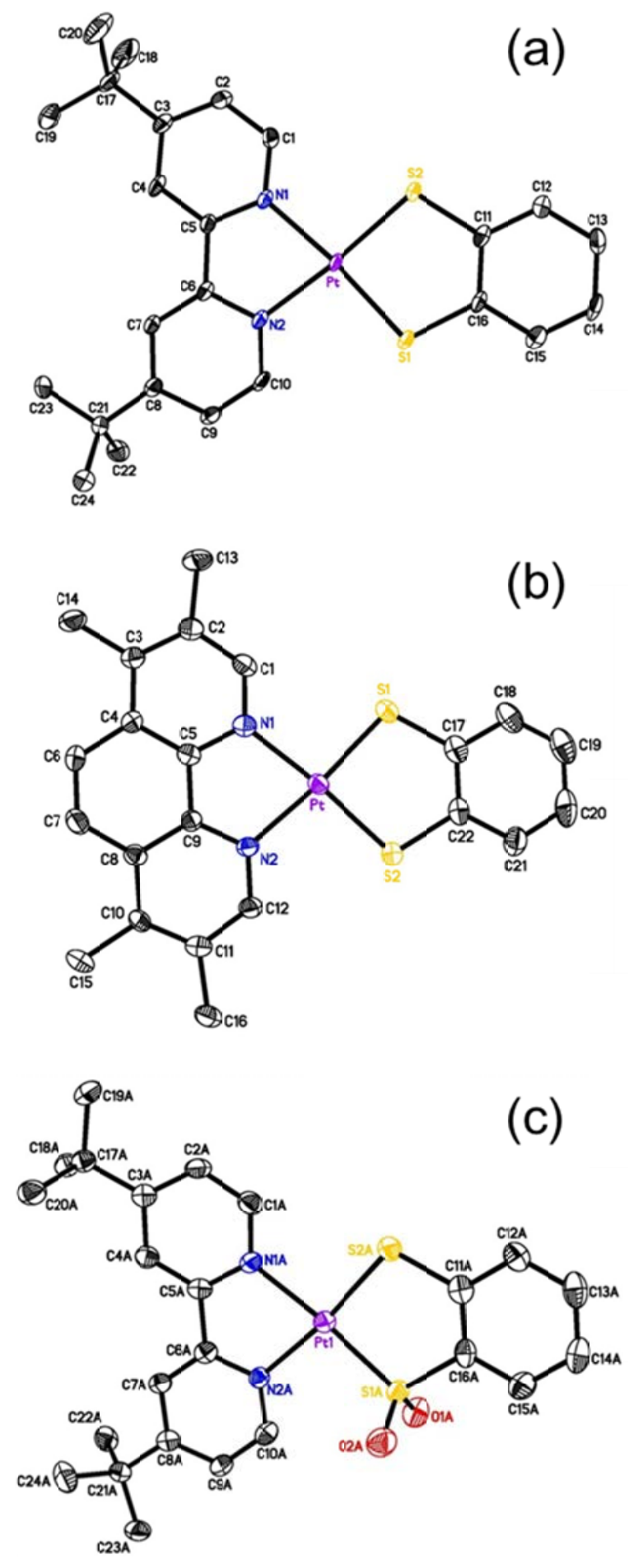

Figure 2: ORTEP drawings of (a) $\mathrm{Pt}(\mathrm{dbbpy})(\mathrm{bdt})$ and (b) $\mathrm{Pt}(\mathrm{tmphen})(\mathrm{bdt})$, (c) $\mathrm{Pt}(\mathrm{dbbpy})\left(\mathrm{bdtO} \mathrm{O}_{2}\right.$ ) (molecule A); ellipsoids at 50\% probability. For clarity, $\mathrm{H}$ atoms are not shown. 


\subsection{Reaction of Pt(dbbpy)(bdt) with $\mathrm{CH}_{3} I$}

Because of its comparatively good solubility, $\mathrm{Pt}(\mathrm{dbbpy})(\mathrm{bdt})$ was selected for reactivity studies with $\mathrm{CH}_{3} \mathrm{I}$ in DMSO, methylene chloride, chloroform, and acetonitrile solutions. Treatment with methyl iodide caused the red-violet solutions to turn yellow. During the reaction, the bipyridyl LC band $(280-310 \mathrm{~nm})$ is essentially preserved, confirming that the diimine ligand remains bonded to the metal. Disappearance of the long-wavelength MMLLCT band is accompanied by the appearance of a less intense charge-transfer band near $460 \mathrm{~nm}$, in accord with reduced electron density on the dithiolate ligand (Figure 1). The resulting $\mathrm{Pt}(\mathrm{dbbpy})\left(\mathrm{CH}_{3} \mathrm{bdt}\right)^{+}$product was isolated from the reaction of $\mathrm{Pt}(\mathrm{dbbpy})(\mathrm{bdt})$ with excess $\mathrm{CH}_{3} \mathrm{I}$, followed by anion metathesis to give the hexafluorophosphate salt. The ${ }^{1} \mathrm{H}$ NMR spectrum showed a methyl proton resonance at $3 \mathrm{ppm}$, in good agreement with chemical shifts observed for other methyl-substituted thioether platinum(II) complexes $[27,65,66]$. The aromatic proton resonances are shifted slightly downfield from those of the parent Pt(dbbpy)(bdt) complex, and there are twice as many resonances, in accord with loss of $C_{2 \mathrm{~V}}$ symmetry due to methylation at an $\mathrm{S}$ atom rather than at the metal center. The accumulated data are consistent with the complete conversion of $\mathrm{Pt}(\mathrm{dbbpy})(\mathrm{bdt})$ to $\mathrm{Pt}(\mathrm{dbbpy})\left(\mathrm{CH}_{3} \mathrm{bdt}\right)^{+}$, as shown in Scheme $3 .{ }^{1} \mathrm{H}$ NMR spectra (Figure 3) recorded during the reaction with one equivalent of $\mathrm{CH}_{3} \mathrm{I}$ in $\mathrm{d}_{6}$-DMSO showed no evidence of an intermediate. The reaction was complete within 2 days, reaching a $\left[\mathrm{Pt}(\mathrm{dbbpy})\left(\mathrm{CH}_{3} \mathrm{bdt}\right)\right]^{+}: \operatorname{Pt}(\mathrm{dbbpy})(\mathrm{bdt})$ mole ratio of $\sim 3$ corresponding to an equilibrium constant of $\sim 10$ at $298 \mathrm{~K}$. Addition of 5 equivalents effectively drove the reaction to completion (Figure S8). With the exception of contributions from excess $\mathrm{CH}_{3} \mathrm{I}$, the electronic and ${ }^{1} \mathrm{H}$ NMR spectra of solutions of $\mathrm{Pt}(\mathrm{dbbpy})(\mathrm{bdt})$ with 5 equivalents of $\mathrm{CH}_{3} \mathrm{I}$ are identical to those obtained with 
1200 equivalents, indicating that methylation of one sulfur greatly reduces the nucleophilicity of the other. Interestingly, both ${ }^{1} \mathrm{H}$ NMR and UV-visible absorption data show that, in the absence of light, the $\mathrm{Pt}(\mathrm{dbbpy})\left(\mathrm{CH}_{3} \mathrm{bdt}\right)^{+}$product is stable and no further reaction occurs. However, irradiation of solutions with $\leq 400 \mathrm{~nm}$ light resulted in decomposition to give unidentified products.

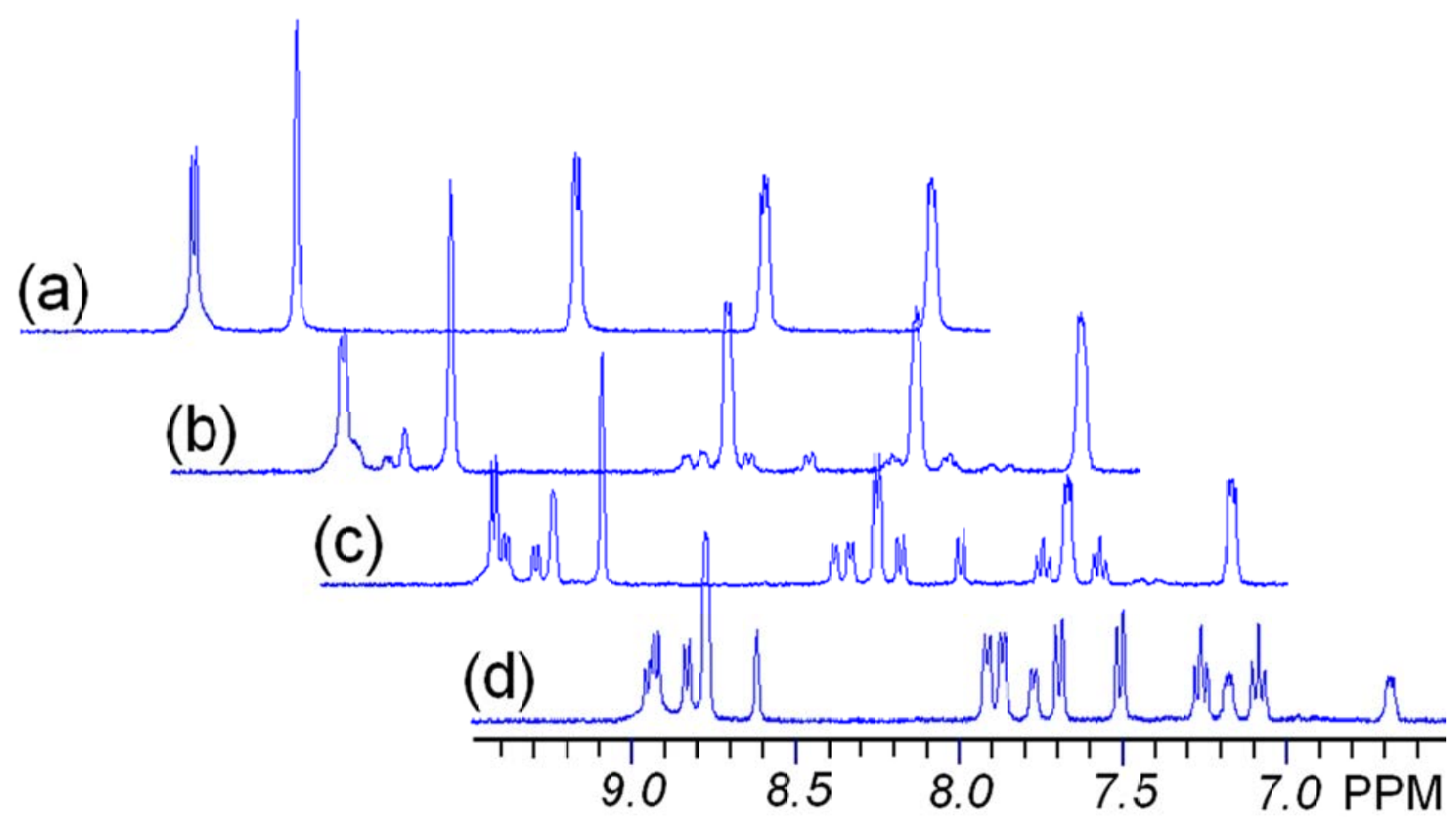

Figure 3: NMR spectra of a $2.5 \mu \mathrm{mol} \operatorname{Pt}(\mathrm{dbbpy})(\mathrm{bdt})$ solution with one equivalent of methyl iodide in $\mathrm{d}_{6}-\mathrm{DMSO},(\mathrm{a})=0 \mathrm{~min} ;(\mathrm{b})=54 \mathrm{~min}$; (c) = $306 \mathrm{~min}$; (d) = $2800 \mathrm{~min}$.

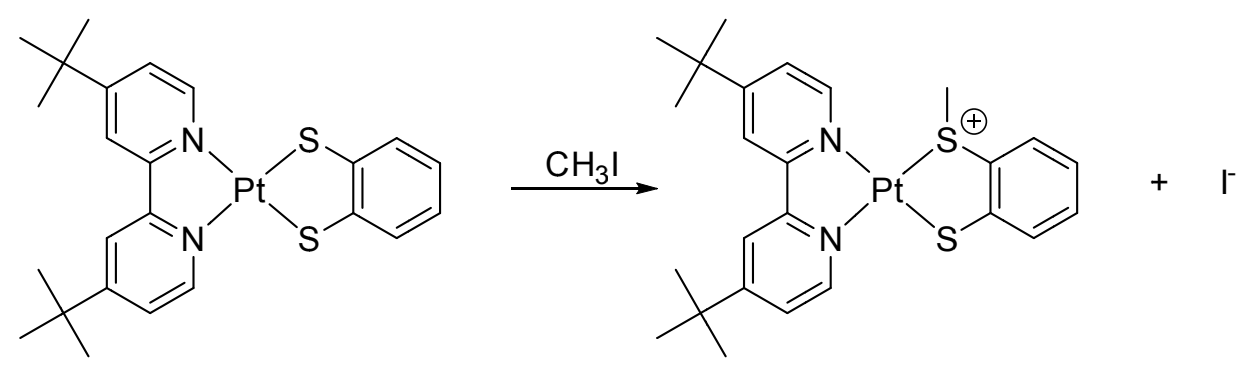

Scheme 3: The reaction of Pt(dbbpy)(bdt) with methyl iodide. 


\subsection{Kinetics of Methylation}

The reaction of $\mathrm{Pt}(\mathrm{dbbpy})(\mathrm{bdt})$ and methyl iodide in chloroform was monitored by UVvisible absorption spectroscopy using stopped-flow methods. Experiments were carried out under pseudo-first order conditions using excess methyl iodide ( $>1000$ fold). Because of the photoinstability of platinum(II) diimine dithiolate complexes in halogenated solvents [67], a reaction mixture typically was probed at a single monochromatically selected wavelength over the $700-400 \mathrm{~nm}$ range. The absorbance vs. time traces recorded at different wavelengths (typically $10 \mathrm{~nm}$ steps) were assembled to give compiled spectral data sets, such as that shown in

Figure 4.

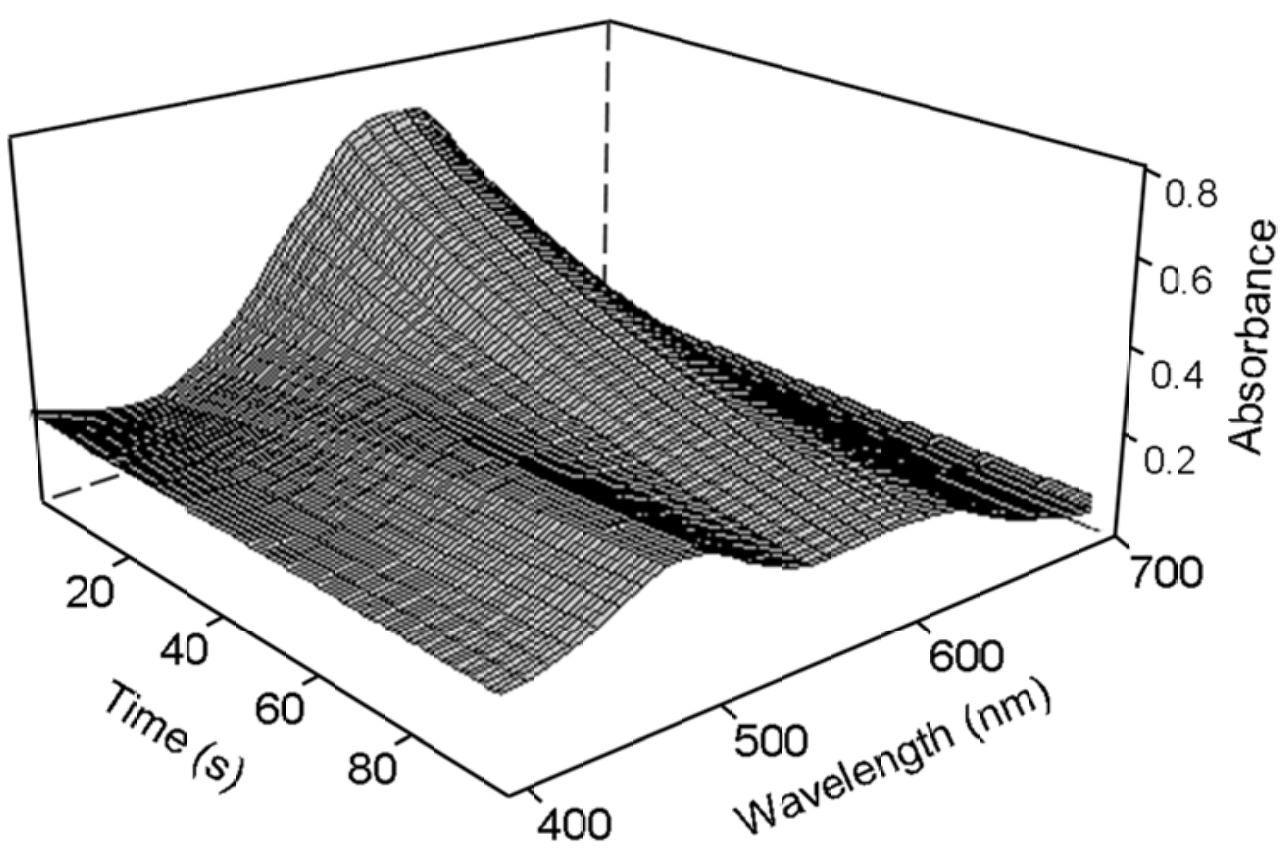

Figure 4: Electronic absorption spectral data of 93.6 $\mu \mathrm{M} \mathrm{Pt(dbbpy)(bdt)} \mathrm{in} \mathrm{chloroform} \mathrm{after}$ mixing with 12,300 equivalents of $\mathrm{CH}_{3} \mathrm{I}$ at $311.2 \mathrm{~K}$. 
The non-linear decrease in intensity of the $\mathrm{Pt}(\mathrm{dbbpy})(\mathrm{bdt})$ band at $580 \mathrm{~nm}$ with time is accompanied by an increase in the product band at $460 \mathrm{~nm}$. Principal component analysis of compiled data sets indicated that just two components are necessary to capture the vast majority of chemically related variance in the data. Single wavelength and compiled data sets were modeled according to a second-order rate law (Equation 5), where $k_{1}$ is the second-order rate constant and $v$ is the rate of reaction $\left(\mathrm{M} \mathrm{s}^{-1}\right)$.

$$
\begin{gathered}
v=k_{1}[\operatorname{Pt}(\mathrm{dbbpy})(\mathrm{bdt})]\left[\mathrm{CH}_{3} \mathrm{I}\right] \\
\text { Equation } 5
\end{gathered}
$$

The compiled data give a rate constant of $0.013 \pm 0.001 \mathrm{M}^{-1} \mathrm{~s}^{-1}$ at $311.2 \mathrm{~K}$ (Table 3 ). From the temperature dependence $(288-314 \mathrm{~K})$, the Arrhenius activation energy $\left(E_{\mathrm{a}}\right)$ was determined to be $51 \pm 3 \mathrm{~kJ} / \mathrm{mol}$ with an Arrhenius pre-exponential factor of $5.2 \pm 0.3 \times 10^{6} \mathrm{M}^{-1} \mathrm{~s}^{-1}$ (Figure S9). The enthalpy $\left(48 \pm 2 \mathrm{~kJ} \mathrm{~mol}^{-1}\right)$ and entropy $\left(-125 \pm 7 \mathrm{~J} \mathrm{~mol}^{-1} \mathrm{~K}^{-1}\right)$ of activation were calculated using transition state theory for nonionic reactants and activated complexes. 
Table 3: Kinetics data for the reaction of $\mathrm{Pt}(\mathrm{dbbpy})(\mathrm{bdt})$ with $\mathrm{CH}_{3} \mathrm{I}$ in chloroform at various temperatures.

\begin{tabular}{|c|c|c|c|c|}
\hline $\begin{array}{c}\text { Temperature } \\
(\mathrm{K})\end{array}$ & $\begin{array}{c}\begin{array}{c}\text { Wavelength } \\
(\mathrm{nm})\end{array} \\
\end{array}$ & $\begin{array}{c}\text { Pt(dbbpy)(bdt) } \\
(\mu \mathrm{M})\end{array}$ & $\begin{array}{l}\mathrm{CH}_{3} \mathrm{I} \\
(\mathrm{M})\end{array}$ & $\begin{array}{l}\begin{array}{c}\text { Fitted } \mathbf{k}_{1} \\
\left(\mathbf{M}^{-1} \mathbf{s}^{-1}\right)\end{array} \\
\end{array}$ \\
\hline \multirow{13}{*}{311.2} & $700-390^{\mathrm{a}}$ & 195 & 0.29 & $0.0137( \pm 10)$ \\
\hline & $700-390^{\mathrm{a}}$ & 93.6 & 1.16 & $0.0122( \pm 2)$ \\
\hline & & 93.6 & 2.01 & $0.0129( \pm 7)$ \\
\hline & \multirow{5}{*}{580} & \multirow{2}{*}{195} & 0.29 & $0.0139( \pm 10)$ \\
\hline & & & 0.56 & $0.0138( \pm 9)$ \\
\hline & & \multirow{2}{*}{93.6} & 0.572 & $0.0123( \pm 2)$ \\
\hline & & & 1.16 & $0.0125( \pm 2)$ \\
\hline & & 70.2 & 2.01 & $0.0129( \pm 8)$ \\
\hline & \multirow{5}{*}{460} & \multirow{2}{*}{195} & 0.29 & $0.0120( \pm 9)$ \\
\hline & & & 0.56 & $0.0121( \pm 9)$ \\
\hline & & \multirow{2}{*}{93.6} & 0.572 & $0.0124( \pm 2)$ \\
\hline & & & 1.16 & $0.0128( \pm 2)$ \\
\hline & & 70.2 & 2.01 & $0.0121( \pm 7)$ \\
\hline 300.9 & \multirow{18}{*}{580} & \multirow{7}{*}{146} & \multirow{7}{*}{0.617} & $0.00618( \pm 31)$ \\
\hline 302.6 & & & & $0.00704( \pm 35)$ \\
\hline 304.5 & & & & $0.00807( \pm 40)$ \\
\hline 306.3 & & & & $0.00879( \pm 43)$ \\
\hline 308.1 & & & & $0.00996( \pm 49)$ \\
\hline 311.2 & & & & $0.0128( \pm 6)$ \\
\hline 311.8 & & & & $0.0131( \pm 6)$ \\
\hline 289 & & \multirow{11}{*}{84.5} & \multirow{11}{*}{0.286} & $0.00277( \pm 4)$ \\
\hline 293.3 & & & & $0.00355( \pm 6)$ \\
\hline 299.1 & & & & $0.00598( \pm 10)$ \\
\hline 300.8 & & & & $0.00612( \pm 10)$ \\
\hline 302.6 & & & & $0.00700( \pm 11)$ \\
\hline 304.5 & & & & $0.00800( \pm 13)$ \\
\hline 306.3 & & & & $0.00848( \pm 14)$ \\
\hline 308.2 & & & & $0.00970( \pm 16)$ \\
\hline 310 & & & & $0.0107( \pm 2)$ \\
\hline 311.8 & & & & $0.0134( \pm 2)$ \\
\hline 313.8 & & & & $0.0154( \pm 2)$ \\
\hline
\end{tabular}

\footnotetext{
${ }^{\mathrm{a}}$ Spectra obtained with $10 \mathrm{~nm}$ data resolution.
}

In contrast to results in chloroform, the kinetics of the reaction of $\mathrm{Pt}(\mathrm{dbbpy})(\mathrm{bdt})$ and methyl iodide in room temperature DMSO were not well-modeled by a second-order rate law (Equation 3). We attribute this to side reactions of DMSO with $\mathrm{CH}_{3} \mathrm{I}$, which are known to produce the metastable oxo-trimethyl-sulfonium ion at competitive rates $[68,69]$. It is probable 
that the trimethyl-sulfonium oxide also can serve as a methyl donor to $\operatorname{Pt}(\mathrm{dbbpy})(\mathrm{bdt})$, which is further expected to complicate the kinetics yet still yield the same final product.

\subsection{Methylation Reaction}

Previously, Fazlur-Rahman and Verkade have reported that the reaction of one equivalent of methyl iodide with $\operatorname{Pt}(\mathrm{L})(\mathrm{bdt})(\mathrm{L}=1,2-\mathrm{bis}($ diethylphosphino))ethane or 1,2bis(dicyclohexylphosphino)ethane) yields exclusively $\mathrm{Pt}(\mathrm{L})\left(\mathrm{CH}_{3} \text { bdt }\right)^{+}$[27]. In conjunction with those observations, the results presented here point to a propensity for methylation of the $\mathrm{bdt}^{2-}$ ligand over oxidative addition of methyl iodide to a platinum(II) center. There is surprisingly little information on the kinetics of thiolate ligand methylation reactions. Burke and Brink reported the activation energy for the reaction of $\mathrm{Ni}(8 \text {-mercaptoquinolate })_{2}$ with methyl iodide in chloroform solution to be $46 \mathrm{~kJ} / \mathrm{mol}$ [36], which is very similar to that of $\mathrm{Pt}(\mathrm{dbbpy})(\mathrm{bdt})$ (51 \pm $2.5 \mathrm{~kJ} / \mathrm{mol})$. Likewise, the rate constants for S-methylation of $\mathrm{M}(\mathrm{mnt})_{2}{ }^{2-}$ at room temperature, where $\mathrm{M}$ is $\mathrm{Cu}\left(2.32 \times 10^{-3} \mathrm{M}^{-1} \mathrm{~s}^{-1}\right), \mathrm{Ni}\left(6.45 \times 10^{-3} \mathrm{M}^{-1} \mathrm{~s}^{-1}\right)$, or Co $\left(9.21 \times 10^{-3} \mathrm{M}^{-1} \mathrm{~s}^{-1}\right)$ [32], are comparable to that for $\mathrm{Pt}(\mathrm{dbbpy})(\mathrm{bdt})$ at $293 \mathrm{~K}\left(3.6 \times 10^{-3} \mathrm{M}^{-1} \mathrm{~s}^{-1}\right)$. Interestingly, in the $\mathrm{M}(\mathrm{mnt})_{2}{ }^{2-}$

case, both $\mathrm{S}$ atoms of the $\mathrm{mnt}^{2-}$ ligand are methylated, and the metal complex product is unstable. In the present case, there is no spectroscopic evidence of an intermediate, and only one $\mathrm{S}$ atom of the $\mathrm{bdt}^{2-}$ ligand is methylated. The accumulated data are consistent with attack of a $\operatorname{Pt}(\mathrm{dbbpy})(\mathrm{bdt})$ sulfur nucleophile on the carbon atom of methyl iodide. Notably, the reaction is second order, and the entropy of activation is substantially less than zero, consistent with an $\mathrm{S}_{\mathrm{N}} 2$ like mechanism. Though involvement of the metal cannot be fully excluded as a possibility, the observation of rather similar kinetic parameters for a range of complexes is consistent with direct 
methylation at the $\mathrm{S}$ atom. However, it should be noted that the rate constant for the reaction of $\operatorname{Pt}(\mathrm{dbbpy})(\mathrm{bdt})$ with methyl iodide is comparable to or less than those of reactions involving oxidative addition of methyl iodide to other $\mathrm{d}^{8}$-electron metal complexes $[31,32,70-76]$. For example, the rate constant for oxidative addition of $\mathrm{CH}_{3} \mathrm{I}$ to $\mathrm{Pt}(\mathrm{bpy})$ (4-thiocresolate) ${ }_{2}\left(\mathrm{CH}_{2} \mathrm{Cl}_{2}\right.$, $\left.2.3 \times 10^{-3} \mathrm{M}^{-1} \mathrm{~s}^{-1}\right)$ [31] at $303 \mathrm{~K}$ is comparable to that for S-methylation of $\mathrm{Pt}(\mathrm{dbbpy})(\mathrm{bdt})$. Thus, the site of attack cannot be reliably inferred from the rate constant alone.

\section{Conclusions}

The results presented here illustrate the susceptibility of platinum(II) diimine dithiolates to chemical oxidation. Notably, kinetic data are consistent with reaction of the metal complex with methyl iodide via an $\mathrm{S}_{\mathrm{N}} 2$ mechanism. Interestingly, $\mathrm{Pt}(\mathrm{phen})(\mathrm{bdt})$ exhibits an exceptionally long excited-state lifetime in fluid solution. The concentration dependence of the lifetime and quantum yield can be rationalized in terms of a self-quenching mechanism. Though sometimes overlooked, the susceptibility to chemical oxidation and the concentration dependence of the photophysical properties of platinum(II) diimine dithiolate complexes have important implications for the construction, characterization and application of photochemical devices based on this class of chromophore.

\section{Acknowledgements}

W.B.C. thanks the National Science Foundation (Grant CHE-1152853) for support of this research. Funding for the SMART6000 diffractometer was through NSF-MRI grant (CHE0215950). 


\section{Appendix A. Supplementary material}

CCDC 1414796-1414798 contains the supplementary crystallographic data for Pt(dbbpy)(bdt),

$\mathrm{Pt}(\mathrm{tmphen})(\mathrm{bdt})$ and $\mathrm{Pt}(\mathrm{dbbpy})\left(\mathrm{bdtO}_{2}\right)$. These data can be obtained free of charge from The

Cambridge Crystallographic Data Centre via www.ccdc.cam.ac.uk/data_request/cif.

Supplementary data associated with this article can be found, in the online version, at

http://dx.doi.org/xxxx.

\section{References}

[1] F.D. Camassei, L. Ancarani-Rossiello, F. Castelli, J. Luminescence, 8 (1973) 71.

[2] G. Matsubayashi, Y. Yamaguchi, T. Tanaka, J. Chem. Soc., Dalton Trans., (1988) 2215.

[3] V.M. Miskowski, V.H. Houlding, Inorg. Chem., 28 (1989) 1529.

[4] J.A. Zuleta, C.A. Chesta, R. Eisenberg, J. Am. Chem. Soc., 111 (1989) 8916.

[5] C. Vogler, B. Schwederski, A. Klein, W. Kaim, J. Organomet. Chem., 436 (1992) 367.

[6] C.W. Chan, L.K. Cheng, C.M. Che, Coord. Chem. Rev., 132 (1994) 87.

[7] J. DePriest, G.Y. Zheng, C. Woods, D.P. Rillema, N.A. Mikirova, M.E. Zandler, Inorg. Chim. Acta, 264 (1997) 287.

[8] W.B. Connick, D. Geiger, R. Eisenberg, Inorg. Chem., 38 (1999) 3264.

[9] E.O. Danilov, I.E. Pomestchenko, S. Kinayyigit, P.L. Gentili, M. Hissler, R. Ziessel, F.N. Castellano, J. Phys. Chem. A, 109 (2005) 2465.

[10] F. Hua, S. Kinayyigit, J.R. Cable, F.N. Castellano, Inorg. Chem., 45 (2006) 4304.

[11] C.J. Adams, N. Fey, M. Parfitt, S.J.A. Pope, J.A. Weinstein, Dalton Trans., (2007) 4446.

[12] H. Guo, M.L. Muro-Small, S. Ji, J. Zhao, F.N. Castellano, Inorg. Chem., 49 (2010) 6802.

[13] J.A. Zuleta, M.S. Burberry, R. Eisenberg, Coord. Chem. Rev., 97 (1990) 47.

[14] S.D. Cummings, R. Eisenberg, J. Am. Chem. Soc., 118 (1996) 1949.

[15] Y. Zhang, K.D. Ley, K.S. Schanze, Inorg. Chem., 35 (1996) 7102.

[16] W.B. Connick, H.B. Gray, J. Am. Chem. Soc., 119 (1997) 11620.

[17] M.A. Baldo, C. Adachi, S.R. Forrest, Phys. Rev. B, 62 (2000) 10967.

[18] T.M. Cocker, R.E. Bachman, Inorg. Chem., 40 (2001) 1550.

[19] J. Brooks, Y. Babayan, S. Lamansky, P.I. Djurovich, I. Tsyba, R. Bau, M.E. Thompson, Inorg. Chem., 41 (2002) 3055.

[20] S.W. Thomas, K. Venkatesan, P. Muller, T.M. Swager, J. Am. Chem. Soc., 128 (2006) 16641.

[21] L. Chassot, E. Mueller, A.V. Zelewsky, Inorg. Chem., 23 (1984) 4249. 
[22] P. Witold, S.D. Cummings, M.A. Mansour, W.B. Connick, D.K. Geiger, R. Eisenberg, Coord. Chem. Rev., 171 (1998) 125.

[23] M. Hissler, W.B. Connick, D.K. Geiger, J.E. McGarrah, D. Lipa, R.J. Lachicotte, R.

Eisenberg, Inorg. Chem., 39 (2000) 447.

[24] W.F. Fleeman, W.B. Connick, Comments Inorg. Chem., 23 (2002) 205.

[25] T. Lazarides, T.M. McCormick, K.C. Wilson, S. Lee, D.W. McCamant, R. Eisenberg, J.

Am. Chem. Soc., 133 (2011) 350.

[26] J. Yang, D.K. Kersi, L.J. Giles, B.W. Stein, C. Feng, C.R. Tichnell, D.A. Shultz, M.L. Kirk, Inorg. Chem., 53 (2014) 4791.

[27] A.K. Fazlur-Rahman, J.G. Verkade, Inorg. Chem., 31 (1992) 5331.

[28] C.-H. Cheng, B.D. Spivack, R. Eisenberg, J. Am. Chem. Soc., 99 (1977) 3003.

[29] C.-H. Cheng, R. Eisenberg, Inorg. Chem., 18 (1979) 2438.

[30] W. Henderson, B.K. Nicholson, R.D.W. Kemmitt, J. Chem. Soc., Dalton Trans., (1994)

2489.

[31] J.A.K. Jawad, F. N.K, Al-Obaidy, J.A. Hammud, F. Al-Azab, J. Organomet. Chem., 599 (2000) 166.

[32] A. Vlcek, Inorg. Chim. Acta, 43 (1980) 35.

[33] D.G. VanDerveer, R. Eisenberg, J. Am. Chem. Soc., 96 (1974) 4994.

[34] D.H. Busch, D.C. Jicha, M.C. Thompson, J.W. Wrathall, E. Blinn, J. Am. Chem. Soc., 86 (1964) 3642.

[35] E. Blinn, D.H. Busch, J. Am. Chem. Soc., 90 (1968) 4280.

[36] J.A. Burke, E.C. Brink, Inorg. Chem., 8 (1969) 386.

[37] J.A. Burke, S.E. Campbell, J. Inorg. Nucl. Chem, 33 (1971) 1163.

[38] J.C. Shoup, J. John A. Burke, Inorg. Chem., 12 (1973) 1851.

[39] D.K. Mills, J.H. Reibenspies, M.Y. Darensbourg, Inorg. Chem., 29 (1990) 4364.

[40] D.C. Goodman, R.M. Buonomo, P.J. Farmer, J.H. Reibenspies, M.Y. Darensbourg, Inorg. Chem., 35 (1996) 4029.

[41] D.C. Goodman, J.H. Reibenspies, N. Goswami, S. Jurisson, M.Y. Darensbourg, J. Am.

Chem. Soc., 119 (1997) 4955.

[42] G. Musie, J.H. Reibenspies, M.Y. Darensbourg, Inorg. Chem., 37 (1998) 302.

[43] M.T. Ashby, J.H. Enemark, D.L. Lichtenberger, Inorg. Chem., 27 (1988) 191.

[44] T.W. Green, R. Lieberman, N. Mitchell, J.A. Krause Bauer, W.B. Connick, Inorg. Chem., 44 (2005) 1955.

[45] H. Jude, J.A. Krause Bauer, W.B. Connick, Inorg. Chem., 44 (2005) 1211.

[46] D. Magde, J.H. Brannon, T.L. Cremers, I. John Olmsted, J. Phys. Chem., 83 (1979) 696.

[47] J.N. Demas, G.A. Crosby, J. Am. Chem. Soc., 92 (1970) 7762.

[48] I.A. Adejoror, T.O. Bamkole, Afr. J. Pure Appl. Chem., 3 (2009) 141.

[49] I.N. Levine, Physical Chemistry, McGraw Hill, Higher Education 2009.

[50] K.D. Hodges, J.V. Rund, Inorg. Chem., 14 (1975) 525.

[51] H. Honda, T. Matsumoto, M. Sakamoto, A. Kobayashi, H.-C. Chang, M. Kato, Inorg.

Chem., 52 (2013) 4324.

[52] A. Vogler, H. Kunkley, Inorg. Chem., 21 (1982) 1172.

[53] C.A. Mitsopoulou, Coord. Chem. Rev., 254 (2010) 1448.

[54] R.P. Sabatini, B. Zheng, W.-F. Fu, D.J. Mark, M.F. Mark, E.A. Hillenbrand, R. Eisenberg, D.W. McCamant, J. Phys. Chem. A, 118 (2014) 10663. 
[55] K.P. Rao, T. Kusamoto, R. Sakamoto, Y. Yamamoto, S. Kume, M. Nihei, H. Oshiob, H. Nishihara, Chem. Commun., 47 (2011) 2330.

[56] E.W. Abel, S.K. Bhargava, K. Kite, K.G. Orrell, V. Sik, B.L. Williams, Polyhedron, 1 (1982) 289.

[57] H. Kunkely, A. Vogler, J. Am. Chem. Soc., 112 (1990) 5625.

[58] K.-T. Wan, C.-M. Che, K.-C. Cho, J. Chem. Soc. Dalton Trans., (1991) 1077.

[59] C.W. Chan, C.M. Che, M.C. Cheng, Y. Wang, Inorg. Chem., 31 (1992) 4874.

[60] C.W. Chan, T.F. Lai, C.M. Che, S.M. Peng, J. Am. Chem. Soc., 115 (1993) 11245.

[61] C.N. Pettijohn, E.B. Jochnowitz, B. Chuong, J.K. Nagle, A. Vogler, Coord. Chem. Rev., $171(1998) 85$.

[62] B. Ma, P.I. Djurovich, M.E. Thompson, Coord. Chem. Rev., 249 (2005) 1501.

[63] G.B. Bachman, L.V. Heisey, J. Am. Chem. Soc., 68 (1946) 2496.

[64] J.M. Bevilacqua, J.A. Zuleta, R. Eisenberg, Inorg. Chem., 33 (1994) 258.

[65] F.R. Hartley, S.G. Murray, W. Leavson, H.E. Soutter, C.A. McAuliffe, Inorg. Chim. Acta, 35 (1979) 265.

[66] F.R. Hartley, S.G. Murray, C.A. McAuliffe, Inorg. Chem., 18 (1979) 1394.

[67] A. Vogler, H. Kunkely, J. Am. Chem. Soc., 103 (1981) 1559.

[68] M.A.G. El-Fayoumy, M.A.O. H. C. Dorn, J. Labelled Compd. Radiopharm., 13 (1977) 433.

[69] A.T.J. Klein, M. Holschbach, Appl. Radiat. Isot., 55 (2001) 309.

[70] J.K. Jawad, R.J. Puddephatt, J. Organomet. Chem., 117 (1976) 297.

[71] J.K. Jawad, R.J. Puddephatt, J. Chem. Soc., Dalton Trans., (1977) 1466.

[72] P.K. Byers, A.J. Canty, M. Crespo, R.J. Puddephatt, J.D. Scott, Organometallics, 7 (1988) 1363.

[73] V. Chauby, J.-C. Daran, C.S.-L. Berre, F. Malbosc, P. Kalck, O.D. Gonzalez, C.E. Haslam, A. Haynes, Inorg. Chem., 41 (2002) 3280.

[74] A. Haynes, P.M. Maitlis, I.A. Stanbridge, S. Haak, J.M. Pearson, H. Adams, N.A. Bailey, Inorg. Chim. Acta, 357 (2004) 3027.

[75] J.M. Wilson, G.J. Sunley, H. Adams, A. Haynes, J. Organomet. Chem., 690 (2005) 6089.

[76] S. Habibzadeh, M. Rashidi, S.M. Nabavizadeh, L.H. Mahmoodi, F. Niroomand, R.J.

Puddephatt, Organometallics, 29 (2010) 82. 
Graphical Abstract for:

Kinetics of the Methylation of a Platinum(II) Diimine Dithiolate Complex

Justin J. Stace, ${ }^{a}$ PJ Ball, ${ }^{b}$ Vikas Shingade, ${ }^{b}$ Sayandev Chatterjee, ${ }^{b}$ Amber Shiveley, ${ }^{b}$ Wendi L. Fleeman, ${ }^{b}$ Aaron J. Staniszewski, ${ }^{\mathrm{b}}$ Jeanette A. Krause, ${ }^{\mathrm{b}}$ William B. Connick ${ }^{*, \mathrm{~b}}$

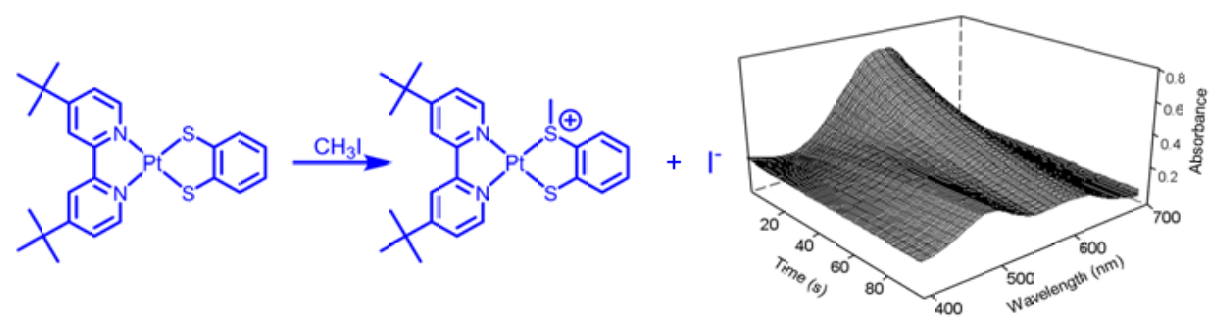

